\title{
HUBUNGAN PSYCHOLOGICAL WELL-BEING DENGAN LONELINESS
}

\author{
Andreas Rantepadang ${ }^{1}$, Ariel Ben Gery ${ }^{2}$ \\ ${ }^{1}$ Pengajar, Faculty of Nursing Universitas Klabat, Manado, Indonesia \\ ${ }^{2}$ Mahasiswa Semester Akhir, Faculty of Nursing Universitas Klabat, Manado, Indonesia \\ Email: rantepadang@unklab.ac.id
}

\begin{abstract}
Loneliness can occur to anyone, especially at a young adult age, including students who have problems in social skills and adapt to the environment. Good psychological well-being can avoid feelings of loneliness. The purpose of this study was to analyze the relationship of psychological well-being with loneliness in overseas students. The research design used is correlative descriptive with cross-sectional approach. 188 respondents were selected through purposive sampling in the span of February to March 2019. The results showed the average psychological well-being of students was at 3.55 with the high category and 2.22 the low category loneliness, while the pearson correlation statistical test showed there was a relationship between psychological well-being and the loneliness $p$ value $.000<0.05$ the correlation value -0.474 included on the closeness of a moderate relationship with a negative direction. Recommendations to students and parents to avoid the emergence of feelings of loneliness need to improve psychological well-being such as positive relationships with others and for further research to analyze the effect of psychological well-being on loneliness.
\end{abstract}

Keywords: loneliness, psychological, studen, well being

\begin{abstract}
Abstrak
Loneliness dapat terjadi pada siapa saja, terlebih pada usia dewasa muda, termasuk mahasiswa yang memiliki masalah dalam kemampuan bersosialisasi dan menyesuaikan diri dengan lingkungan. Psychological well-being yang baik dapat terhindar dari perasaan loneliness. Tujuan dari penelitian ini adalah untuk menganalisa hubungan psychological well-being dengan loneliness pada mahasiswa rantau. Desain penelitian yang digunakan yaitu deskriptif korelatif dengan pendekatan cross-sectional. 188 responden terpilih melalui purposive sampling dalam rentang waktu Februari sampai Maret 2019. Hasil penelitian menunjukkan rata-rata psychological well-being mahasiswa berada pada 3.55 dengan kategori tinggi dan loneliness 2.22 kategori rendah, sedangkan pada uji statistik pearson correlation menunjukkan ada hubungan antara psychological well-being dengan loneliness $\mathrm{p}$ value $.000<0.05$ nilai korelasi -0.474 termasuk pada keeratan hubungan sedang dengan arah negatif. Rekomendasi kepada mahasiswa maupun orang tua agar terhindar dari perasaan loneliness perlu meningkatkan psychological well- being seperti relasi positif dengan orang lain dan bagi penelitian selanjutnya untuk menganalisa pengaruh psychological well-being terhadap loneliness.
\end{abstract}

Kata Kunci: loneliness, mahasiswa, psychological, well being 


\section{Pendahuluan}

Loneliness merupakan masalah yang umum terjadi dan sudah menjadi bagian dari kehidupan manusia. Gangguan ini tidak terkecuali dapat menyerang semua rentang usia dan terjadi seiring dengan pengalaman hidup yang dialami oleh individu (Bernard, 2013).

Menurut Miller (2011), loneliness yang berkepanjangan bisa berbahaya bagi tubuh karena dapat membuat perubahan pada sistem imun. Hal ini didukung oleh Steptoe, Shankar, Demakakos, dan Wardle (2013), bahwa loneliness memiliki keterikatan dengan penyakit jantung serta peningkatan tekanan darah. Edwards, dkk. (2016), menyatakan 1 dari 10 orang di dunia sering merasakan loneliness yang beresiko berlanjut depresi. Selain dilansir dari AVIVA (2014), sebuah survei menyeluruh di Inggris tahun 2014 mendapati bahwa 48\% dari kelompok usia 18-34 tahun sering mengalami loneliness.

Matthews, et al, (2016) berpendapat bahwa usia dewasa muda lebih cenderung mengalami loneliness dikarenakan pada tahap transisi dari masa remaja memiliki tingkat kebutuhan yang sangat tinggi untuk memiliki teman dekat dan pasangan. Srivastava dan Agarwal (2014) menambahkan loneliness memiliki keterikatan dengan kemampuan bersosialisasi, buruknya hubungan interpersonal, harga diri rendah, sifat pemalu dan ketidakmampuan untuk menyesuaikan diri dengan lingkungan sosial.

Mahasiswa juga tidak terlepas dari resiko mengalami loneliness terlebih pada mahasiswa rantau. Pijpers (2017), berpendapat, bahwa mahasiswa memiliki resiko yang tinggi untuk mengalami kesepian selain karena tuntutan sosial yang tinggi terlebih khusus karena adanya perasaan homesicknes. Sejalan dengan Ind (2016), yang menyatakan bahwa loneliness terjadi pada orang-orang yang mengalami perubahan kehidupan seperti meninggalkan rumah yang cenderung terjadi pada mahasiswa rantau (Mahasiswa yang jauh dari orang tua).

Tidak semua mahasiswa rantau mengalami loneliness karena memiliki psychological well-being yang baik. Huppert (2009) berpendapat psychological well-being adalah bagaimana seseorang dapat merasa bahagia dan bekerja secara efektif, serta dapat menerima keadaan buruk (kecewa, gagal, berduka) sebagai bagian dari kehidupan. Opree, Buijzen, dan Reijmersdal (2018) menambahkan bahwa psychological well-being adalah kemampuan dari diri seseorang serta wujud nyata dari potensi yang dimiliki individu tersebut yang bersifat jangka panjang. Menurut Ryff (2014) psychological well-being terbagi atas enam dimensi yaitu environmental mastery, personal growth, purpose in life, self acceptance, autonomy dan positive relation with other.

Semakin baik psychological well-being seseorang dapat membantu menurunkan loneliness dari individu tersebut. Penelitian dari Nordin dan Talib (2009), pada kalangan pelajar dibeberapa universitas Malaysia menunjukkan bahwa adanya hubungan antara well-being dan loneliness. Sama halnya dengan penelitian yang dilakukan oleh Halim dan Dariyo (2016), tentang hubungan psychological well-being dengan loneliness pada mahasiswa yang merantau didapati hasil nilai $p=0.000<0.05$ dan nilai $\mathrm{r}=-0.659$ yang berarti terdapat hubungan negatif yang signifikan antara psychogical well-being dengan loneliness dengan kata 
Volume 4, No.1, April 2020

lain semakin baik psychological well-being maka akan semakin rendah adanya loneliness.

Berdasarkan studi literatur yang ada, usia dewasa muda lebih cenderung untuk mengalami loneliness. Di Universitas Klabat sendiri bayak mahasiswa rantau yang berasal dari berbagai daerah di Indonesia, mereka tinggal di asrama dimana mereka tinggal jauh dari orang tua dan belum pernah dilakukan penelitian. Maka dari itu tujuan dari penelitian ini adalah menganalisa hubungan psychological well-being dengan loneliness pada mahasiswa rantau.

\section{Metode Penelitian}

Rancangan penelitian dalam penelitian ini menggunakan metode deskriptif korelasi dengan pendekatan cross sectional yang merupakan cara pengambilan data dengan sekali waktu untuk menentukan waktu pengukuran/observasi data (Aprianti, 2012).

Populasi dalam penelitian ini adalah seluruh mahasiswa rantau di Universitas Klabat yang berjumlah 753 mahasiswa, yang tergabung dari berbagai daerah asal dan fakultas. Cara pengambilan sampel purposive sampling yaitu teknik penetapan sampel dari antara populasi berdasarkan kehendak peneliti agar sesuai dengan tujuan penelitian dan dapat mewakili populasi. Kriteria inklusi: Mahasiswa rantau baik lakilaki maupun perempuan yang aktif berkuliah pada saat peneliti melakukan perkuliahan, berusia dewasa muda (18-24 tahun) bersedia menandatangani informed consent sedangkan kriteria eksklusi: mahasiswa rantau yang sudah menikah, tinggal dengan relative serta mahasiwa yang tidak mengisi kuesioner dengan benar. Penentuan jumlah sampel menggunakan rumus slovin dengan
Onine Joumal: hitp://ejournal unklab. ac id/index. php/nutix

menggunakan margin error sebesar 5\% maka dari itu jumlah sampel adalah 262 responden tetapi ada 72 responden yang mengisi jawaban tidak lengkap pada kuesioner sehingga jumlah responden yang datanya dianalisa adalah 188 responden.

Pada penelitian ini menggunakan uji Pearson's correlation dimana menguji dua variabel apakah ada hubungan dengan jenis data keduanya adalah sama yaitu interval dan berdistribusi normal (Sujarweni, 2014)

Untuk mengukur psychological well-being peneliti mengadopsi kuisioner psychological well-being scale (PWBS) dari Ryff yang terdiri dari empat puluh dua butir pernyataan yang terdiri dari enam dimensi dengan nilai releabilitas dimensi satu (otonomi) dengan alpha cronbach $(\alpha)=0.726$; dimensi dua (pertumbuhan diri) dengan alpha cronbach $(\alpha)=0.601 ;$ dimensi tiga (tujuan hidup) Cronbach's alpha $(\alpha)=$ 0.730; dimensi empat (relasi positif) Cronbach's alpha $(\alpha)=0.649$; dimensi lima (penerimaan diri) Cronbach's alpha $(\alpha)=$ 0.712; dimensi enam (penguasaan lingkungan) Cronbach's alpha $(\alpha)=0.571$, sedangkan untuk mengukur loneliness diadopsi dari penelitian Halim dan Dariyo (2016). Kuesioner loneliness terdiri dari 27 pernyataan dengan nilai reliabilitas loneliness Cronbach's alpha $(\alpha)=0.943$. Strategi analisis data yang telah dilakukan dalam penelitian ini terbagi dalam beberapa tahap, yaitu preanalysis phase, preliminary assessment, preliminary action, principal analysis, interpretive phase (Polit and Beck, 2012).

\section{Hasil Penelitian}

Tabel 1 Rata-rata Psychological Well-being dan Loneliness 
Responden pada penelitan ini adalah mahasiswa-mahasiswi Universitas Klabat yang berada pada dewasa awal dengan rentang umur 20-30 tahun. Berdasarkan tabel 1 rata-rata psychological well-being mahasiswa berada pada 3.55 dengan kategori tinggi dan loneliness 2.22 kategori rendah.

Tabel 2.

\section{Hasil Uji Pearson Correlation}

\begin{tabular}{lll}
\hline $\mathrm{N}$ & $\begin{array}{l}\text { Pearson } \\
\text { Correlation }\end{array}$ & $\mathrm{p}$-value \\
\hline 188 & $-0.474 * *$ & .000 \\
\hline **corelation is significant at the & 0.01 level (2 tailed)
\end{tabular}

Pada tabel 2 Hasil uji statistik pearson correlation menunjukkan ada hubungan antara dua variabel yaitu variabel psychological well-being dengan Loneliness p-value $.000<0.05$ dan nilai koefisien korelasi $\mathrm{r}=-0.474$ yang menunjukkan derajat/keeratan hubungan sedang, dengan arah hubungan negatif.

\section{Pembahasan}

Rata-rata psychological well-being mahasiswa berada pada kategori tinggi dan loneliness kategori rendah, serta ada hubungan antara dua variabel dan derajat/keeratan hubungan sedang, dengan arah hubungan negatif. Hal ini berarti semakin tinggi psychological well-being maka kecenderungan mahasiswa untuk memiliki perasaan loneliness semakin rendah. Demikian pula sebaliknya semakin rendah psychological well-being semakin tinggi mahasiswa untuk memiliki perasaan loneliness (Halim \& Dariyo, 2016).

Hasil penelitian ini didukung oleh Bhagchandani (2017) yang menyatakan semakin tinggi tingkat psychological wellbeing seseorang maka akan semakin

\begin{tabular}{llll}
\hline Variabel & $\mathrm{N}$ & Mean & Interpretasi \\
\hline $\begin{array}{l}\text { Psychological } \\
\text { well-being }\end{array}$ & 188 & 3.55 & Tinggi \\
Loneliness & 188 & 2.22 & Rendah
\end{tabular}

menurunkan perasaan negatif termasuk lonelines. Hasil penelitian ini juga sejalan dengan penelitian yang dilakukan oleh Nordin dan Talib (2009), pada kalangan pelajar di beberapa universitas Malaysia menunjukkan bahwa adanya hubungan antara well-being dan loneliness dengan nilai $p=0.000<0.05$ dan nilai $\mathrm{r}=-0.239$. Sama halnya dengan penelitian yang dilakukan oleh Halim dan Dariyo (2016), tentang hubungan psychological well-being dengan loneliness pada mahasiswa yang merantau didapati hasil nilai $\mathrm{p}=0.000<0.05$ dan nilai $\mathrm{r}=-0.659$ yang berarti terdapat hubungan negatif yang signifikan antara psychogical well-being dengan loneliness dengan kata lain semakin baik psychological well-being maka akan semakin rendah adanya loneliness.

Keterbatasan penelitian ini kurangnya penjelasan dalam pengisian kuesioner sehingga dari 262 kuesioner yang dijalankan 188 kuesioner yang dijawab dengan lengkap dan benar, 72 kuesioner yang tidak dianalisa karena memberi jawaban tidak lengkap pada kuesioner.

\section{Kesimpulan}

Terdapat hubungan yang signifikan antara psychological well-being dengan loneliness dengan arah negatif, yang berarti semakin tinggi psychological well-being mahasiswa maka perasaan loneliness yang dirasakan semakin rendah.

Saran untuk penelitian selanjutnya adalah menambahkan uji pengaruh psychological well-being terhadap loneliness serta perlu penjelasan yang jelas dalam pengisian 
kuesioner supaya tidak banyak kesalahan dalam pengisian kuesioner sebagaimana pada penelitian ini.

\section{Daftar Pustaka}

Aprianti, I. (2012). The correlation between perceived social support and psychological well-being among first-year migrant students at Universitas Indonesia. (Document ID 20320186)

AVIVA. (2014) The aviva health check UK Report. [Online] Available from: www.aviva.co.uk

Bernard, S. (2013). Loneliness and social isolation among older people in north yorkshire. Retrieved from https://www.york.ac.uk/inst/spru/res earch/pdf/Lone.pdf

Bhagchandani, $\mathrm{R}$ (2017). Effect of loneliness on the psychological wellbeing of college student. International Journal of Social Science and Humanity, 60-64. Doi: 10.18178/ijssh.2017.7.1.796

Edwards, J., Goldie, I., Elliott, I., Breedvelt, J., Chakkalackal, L., \& Foye, U. (2016). Relationships in the 21st Century. London: Mental Health Foundation.

Halim, C. F., \& Dariyo, A. (2016, Desember). Hubungan psychological well-being dengan loneliness pada mahasiswa yang merantau. Jurnal Psikogenesis, 4, 170-181.

Huppert, F. A. (2009). Psychological wellbeing: evidence regarding its causes and consequences. Applied Psychology: Health and Well-Being, 137-164. doi:10.1111/j.17580854.2009.01008.x

Ind, J. (2016). Loneliness accident or injustice? oxford. Retrieved from http://joind.co.uk/lonelinessaccident-or-injustice/

Matthews, T., Danese, A., Wertz, J., Odgers, C. L., Ambler, A., Moffitt, T. E., \& Arseneault, L. (2016, September 4). Social isolation, loneliness and depression in young adulthood: a behavioural genetic analysis. doi:10.1007/s00127-016-1187-7

Miller, G. (2011, January 14). Why loneliness is hazardous to your health. Science. 331, 138-140.

Nordin, N. M., \& Talib, M. A. (2009). Kesunyian dan kesejahteraan psikologi di kalangan pelajar universiti di Malaysia. Jurnal Psikologi Malaysia, 27-37.

Pijpers, J. (2017). Loneliness among students in higher education: influencing factors. Amsterdam: VU Amsterdam.

Polit \& Beck, (2012). Nursing research: generating and assessing evidence for nursing practice. Lippincott Williams and Wilkins, Ninth edition.

Ryff, C. D. (2014). Psychological wellbeing revisited: advances in the science and practice of eudaimonia. Psycotherapy and Psychomatics, 1028.

Steptoe, A., Shankar, A., Demakakos, P., \& Wardle, J. (2013, April 9). Social isolation, loneliness, and all-cause mortality in older men and women. PubMed, 110, 5797-5801.

Srivastava, N., \& Agarwal, S. (2014, June 3). Loneliness Among Young Adults: A Comparative Study. II(3).

Sujarweni, V. (2014). Metodologi penelitian keperawatan. Yogyakarta: Penerbit Gava Media 